\title{
A HISTÓRIA DISCIPLINAR DA LINGUÍSTICA A PARTIR DA IMPLEMENTAÇÃO DE UMA POLÍTICA DE FUNDOS DOCUMENTAIS
}

\section{THE DISCIPLINARY HISTORY OF LINGUISTICS FROM THE IMPLEMENTATION OF A DOCUMENTARY FUNDS POLICY}

\author{
Taís da Silva Martins ${ }^{1}$
}

\begin{abstract}
Resumo: O presente trabalho tem por objetivo apresentar algumas reflexões e apontamentos trazidos à tona sobre a história disciplinar da Linguística, a partir da implementação de uma política de Fundo Documental realizada no/pelo Laboratório Corpus. Entre os Fundos Documentais que estão sob a responsabilidade desse laboratório, temos o Fundo Documental Aldema Menine Mckinney e o Fundo Documental Neusa Carson, duas professoras, pesquisadoras e linguistas gaúchas que atuaram na UFSM e também em território indígena (em questões como descrição linguística e alfabetização, por exemplo) e são os primeiros dados e fatos por nós perscrutados durante a constituição e organização desses acervos que aqui figuram.

Palavras-chave: fundo documental; Linguística; História; Políticas Linguísticas.
\end{abstract}

Abstract: This paper aims to present some notes and reflections on the disciplinary history of linguistics from the implementation of a Documentary Fund policy held at/by Corpus Laboratory. Among the Documentary Funds that are under the responsibility of the Laboratory we have Aldema Menine Mckinney Documentary Fund and Neusa Carson Documentary Fund. They are two professors, researchers and linguists from Rio Grande do Sul, who worked at UFSM and also in indigenous territory whose language is Makushi, where they studied issues such as language description and literacy. These are the first data and facts we have researched during the establishment and organization of these collections that appear here.

Keywords: Documentary Funds; Linguistics; History; Linguistic Policies.

"Consideramos que ler e escrever é a segunda independência do povo indígena. A primeira independência é a terra, a terra demarcada, a terra garantida, a terra na extensão que o índio precisa" (Continuando o Caminho, 1987, p. 09)².

\section{Algumas considerações necessárias sobre a criação de uma política de arquivo para Fundos Documentais}

No trabalho que venho realizando no Laboratório Corpus Laboratório de Fontes de Estudos da Linguagem (PPGL/UFSM), estou

1 Pós-Doutoranda em Estudos Linguísticos - bolsista FAPERGS/CAPES (DOCFIX), Laboratório Corpus, UFSM. E-mail:taissmartins1@gmail.com

${ }^{2}$ Extraído do texto coletivo "O mundo está mudando", produzido por professores indígenas das comunidades Macuxi, Wapixana e Taurepáng. O texto foi publicado no livro manuscrito Witin Komanîpî Ematauwîrî (título em português: Continuando o Caminho), material este que faz parte do acervo do Fundo Documental Aldema Menine Mckinney (FDAMM). 
inserida no projeto de pesquisa Linguística no sul: estudos das ideias e organização da memória, coordenado pela professora Amanda Eloina Scherer. Tal projeto tem, entre seus objetivos, a implementação de uma política de fundos documentais que, de acordo com Scherer, é pensada com a finalidade de:

[...] fomentar uma política de criação de Fundo Documental no interior da instituição, pensando inicialmente na história disciplinar da Linguística, nosso objeto de estudo, mas visando algo maior nas relações que se estabelecem entre as diferentes áreas de produção do conhecimento e os trabalhos desenvolvidos por pesquisadores que dedicam toda uma vida profissional em prol da universidade e têm de fato um imenso legado histórico que precisa ser preservado, tratado, arranjado para estar disponível à consulta dos pesquisadores que estamos formando (SCHERER, 2012, s.p).

É isso que faz com que, atualmente, uma das temáticas que tem envolvido boa parte dos trabalhos no Laboratório Corpus diga respeito à política de arquivo para Fundos Documentais. Scherer, Petri et al. (2013, s.p.), a respeito do trabalho acadêmico-científico no Laboratório Corpus, colocam que:

[...] nos últimos tempos, estamos concebendo um projeto de criação de um Centro de Documentação e Memória composto por vários setores, entre eles, o de Fundos Documentais e Acervos. O primeiro fundo a ser pensado e criado foi o Fundo Documental Neusa Carson (FDNC), designado pelo nome de uma importante linguista do sul do país, que viveu e trabalhou na UFSM e na PUC/RS nas décadas de 70 e 80 , contribuindo para a institucionalização e disciplinarização da Linguística entre nós e tendo uma participação nacional e estrangeira importantíssima no desenvolvimento de pesquisas no campo da descrição de línguas indígenas, mais precisamente o Macuxi, em Roraima.

Após a criação e implementação desse primeiro fundo documental, o FDNC, iniciou-se a captação de outros acervos pessoais e arquivos para compor o futuro Centro de Documentação, idealizado pelos pesquisadores do Laboratório Corpus. Recebemos a doação do acervo pessoal do prof. Michael Phillips $^{3}$ sobre William Blake, o qual está sob a responsabilidade do pesquisador Prof. Dr. Enéias Farias Tavares 4 . Também, ainda em de agosto de 2012, foi assinado o Protocolo de Intenção de Doação do acervo pessoal da professora pesquisadora Maria Luiza Ritzel Remédios por João Antônio Remédios, seu filho, ao Laboratório Corpus.

Dando continuidade à política de criação e implementação de fundos documentais fomentada pelo Laboratório Corpus, o trabalho que venho desenvolvendo diz respeito à criação do Fundo Documental Aldema Menine

3 University of York.

${ }^{4}$ Professor do Departamento de Letras Clássicas, Filologia e Linguística da UFSM e pesquisador do Laboratório Corpus. 
Mckinney $^{5}$ (FDAMM), professora formada em Letras, mestre em Linguística e professora durante mais de 25 anos do Departamento de Metodologia do Ensino do Centro de Educação da Universidade Federal de Santa Maria. A professora Aldema atuou em diversos programas e projetos voltados para a questão educacional indígena, rural e de zona fronteiriça, tendo sido também pró-reitora de assuntos estudantis da UFSM.

A vida profissional da professora Aldema retrata um momento particular da cena político-educacional da UFSM, quando essa instituição investia em cursos de graduação no Estado de Roraima, o que contribuiu posteriormente para a criação da Universidade Federal de Roraima. Assim sendo, resgatar, recuperar, organizar e trazer à tona dados e fatos referentes à história profissional dessa pesquisadora também possibilita "trazer à tona uma parte da história da UFSM, uma parte da história do ensino superior no Brasil e porque não dizer da história da educação nacional" (SCHERER, PETRI, et al, 2013, s.p). Isso porque compreendemos, de acordo com Scherer, Petri et al. (Id.Ibid.), que "pensar um fundo documental é, talvez, abrir a possibilidade de que se reconstruam caminhos já percorridos e marcados por acontecimentos discursivos em diferentes pontos da caminhada do pesquisador que dá nome ao fundo".

O FDAMM é constituído por acervo doado pela própria pesquisadora. Fazem parte desse acervo livros, textos, diários de viagem, relatórios técnico-científicos e um grande número de materiais produzidos durante o período em que a pesquisadora atuou diretamente com educação indígena (cartilhas, livros produzidos por alunos indígenas, etc.).

Estamos ainda em fase de organização e implementação desse Fundo Documental, haja vista que recebemos a doação do material da professora Aldema ainda no final de novembro de 2012. Neste momento, estamos realizando todos os procedimentos técnicos ${ }^{6}$ necessários, os mesmos que já foram empregados no outro Fundo Documental do Laboratório Corpus, como higienização, catalogação, arranjo, etc.

\section{O Fundo Documental Neusa Carson e o Fundo Documental Aldema Menine Mckinney: diferentes recortes, diferentes olhares sobre uma mesma realidade linguística}

A partir dos primeiros olhares que lançamos durante esta fase de constituição e organização dos arquivos do FDNC E FDAMM, trazemos aqui

\footnotetext{
5 Nome atual da referida professora, que anteriormente assinava como Aldema Menine Trindade, como poderemos ver nos recortes aqui apresentados.

${ }^{6}$ Trabalho realizado pela equipe de arquivologia, sob a coordenação da Arquivista Carla Saldanha da Silva.
} 
alguns dados e fatos ${ }^{7}$ que, de algum modo, estão destacando-se, tornando-se visíveis, chamando a nossa atenção. É como se, a cada olhar que lançássemos ao arquivo, ele tomasse vida e mostrasse a direção que devemos tomar. Não trazemos aqui uma pesquisa pronta e acabada tampouco análises finais, e sim alguns exemplos de direções, possibilidades de trajetos de pesquisa que a constituição desses arquivos tem nos apontado.

Os documentos que para nós se destacaram dos demais e que foram constituindo um primeiro corpus de pesquisa foram justamente aqueles que diziam respeito a um dos poucos momentos dos quais temos conhecimento: o momento em que o trabalho acadêmico-profissional de Neusa Carson e de Aldema Menine Mckinney, duas professoras da UFSM, formadas em Letras, mas com trajetórias distintas na instituição, interligam-se de maneira efetiva em um território indígena (de língua Macuxi), a partir de um projeto de formação de professores indígenas, no ano de 1987, que culminou na constituição de um projeto de alfabetização bilíngue.

Ambas possuem uma trajetória diferenciada de trabalho neste território. A Professora Neusa Carson, professora do Centro de Artes e Letras, linguista, especialista em línguas indígenas, com uma produção extensa na área, foi para o território para conhecer a língua e descrevê-la. Já Aldema Mckinney, professora do Centro de Educação, do Departamento de Metodologia de Ensino, mestre em Linguística, formada pela segunda turma de pós-graduação da PUCRS sob a orientação do Prof. Ir. Elvo Clemente, com trabalho voltado para o ensino de língua em região (zona) de fronteira e em educação no campo, foi inicialmente para Roraima para ministrar disciplinas de Didática e Estágio, no Curso de Letras que a UFSM lá possuía.

No tocante ao projeto em que ambas estiveram envolvidas, a partir de dados oficiais do Núcleo de Educação Indígena de Roraima $(\mathrm{NEI})^{8}$, que foi fundado no ano de 1986, podemos definir institucionalmente o papel de cada uma das pesquisadoras na elaboração de uma política de criação de uma educação indígena bilíngue, a qual desencadeou na produção das primeiras cartilhas de alfabetização em língua Macuxi. Vejamos:

Para implantar o ensino bilíngue nestas comunidades o Núcleo solicitou a
assessoria das pesquisadoras e linguistas Neusa Carson e Bruna Franchetto.
A primeira subsidiaria os professores falantes do Macuxi na definição da
ortografia da língua, a segunda, começaria a análise e o estudo do idioma
Wapixana, por não ter sido ainda estudado cientificamente. Outra importante

7 Os recortes jornalísticos aqui apresentados são recorrentes nos dois acervos; já os recortes
referentes às cartilhas são referentes ao acervo do FDAMM. Não apresentamos o número de série
dos materiais aqui apresentados, pois ambos ainda estão em fase de arranjo, embora o FDNC
esteja em fase de finalização desse processo.
${ }^{8}$ Fonte: Histórico do Núcleo de Educação Indígena (ano 1986-1987), elaborado pelas professoras
Izaíra Machado e Mari Luiza Reis. Documento que consta no FDAMM. 
assessoria nos seria concedida pela educadora e linguista Aldema Trindade, que forneceria aos professores-alfabetizadores indígenas os elementos necessários para elaboração das cartilhas em Macuxi e em língua portuguesa adaptada à realidade indígena e de outros recursos didáticos para o período da alfabetização (MACHADO; REIS, 1987, p. 03) 9

No mesmo documento, a saber, o Histórico do NEI dos anos de 1986 e 1987, Machado e Reis afirmam ainda que, na primeira etapa do trabalho de elaboração das cartilhas, realizada em março, Neusa Carson ministrou um curso sobre elementos linguísticos do Macuxi para doze professores que "falavam fluentemente a língua materna" (Ibid., p. 04) e que, posteriormente, seriam responsáveis pela elaboração da cartilha Macuxi. Na sequência, também em março, a professora Aldema ministrou um curso sobre a elaboração de material didático para 23 professores indígenas ${ }^{10}$, cujo objetivo principal era iniciar o processo de elaboração da Cartilha em Macuxi e a adaptação da cartilha em língua portuguesa à realidade sociocultural indígena.

Conforme Reis e Machado (1987), os dois materiais foram assim desenvolvidos: os alfabetizadores indígenas responsáveis por sua elaboração dividiram-se em dois grupos, os que falavam fluentemente o idioma Macuxi e ficaram responsáveis pela produção da cartilha nesta língua (Makusiyami'ya Teserukon ko'mannîpî - os índios conservam sua tradição), e os demais, pela produção da cartilha em língua portuguesa adaptada à realidade indígena (Aprendendo com a Natureza).

O processo de desenvolvimento e aperfeiçoamento desse material didático deu-se no decorrer do primeiro semestre de 1987 e culminou, em junho do mesmo ano, em mais uma etapa de trabalho. O documento redigido por Reis e Machado salienta que "a montagem final das cartilhas foi feita pela professora que assessorou a elaboração das mesmas" (Ibid., p. 15).

Os documentos oficiais a que tivemos acesso buscam evidenciar que o papel das assessoras foi restrito à coordenação das discussões e à concessão de informações solicitadas pelos professores indígenas, autores legítimos dos materiais. Entretanto, na mídia impressa que circulava na época, em detrimento da autoria do material didático, o destaque era dado à elaboração dessas primeiras cartilhas, com ênfase no papel das assessoras e, por vezes, da Secretaria da Educação e do NEI, como podemos ver nos recortes a seguir (Figuras 01 e 02):

\footnotetext{
${ }^{9}$ Grifos nossos.

10 Segundo Aldema Menine Mckinney, em entrevista a integrantes do Laboratório Corpus (disponível no acervo digital do Laboratório), o primeiro grupo de professores que participou desses Cursos era formado por professores de cinco etnias, sendo que muitos deles, hoje, são diretores de educação indígena e/ou professores universitários. Cabe ressaltar que a primeira professora indígena que cursou mestrado, a Prof. Rosely Fialho, realizou este curso em Santa Maria, sob a orientação da Prof. ${ }^{a}$ Aldema.
} 


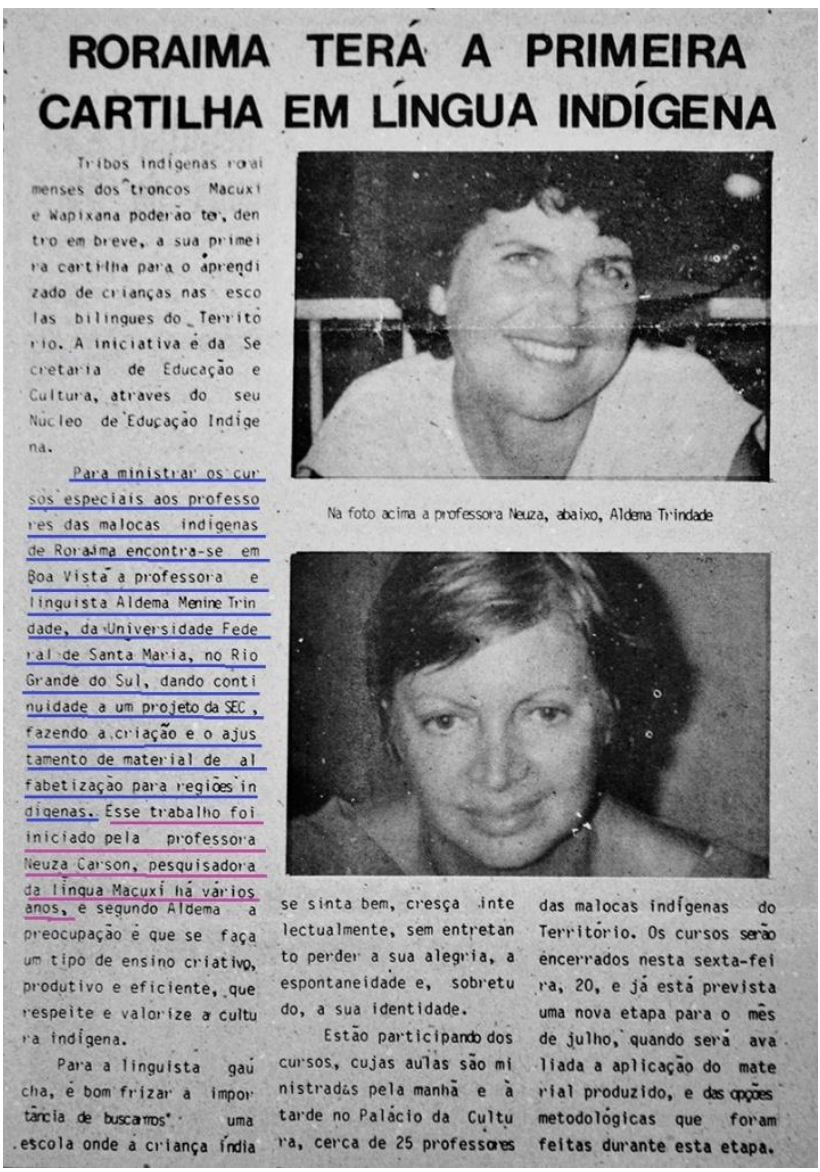

Figura 01 - Jornal Tribuna de Roraima, de 20 de março de 1987. 


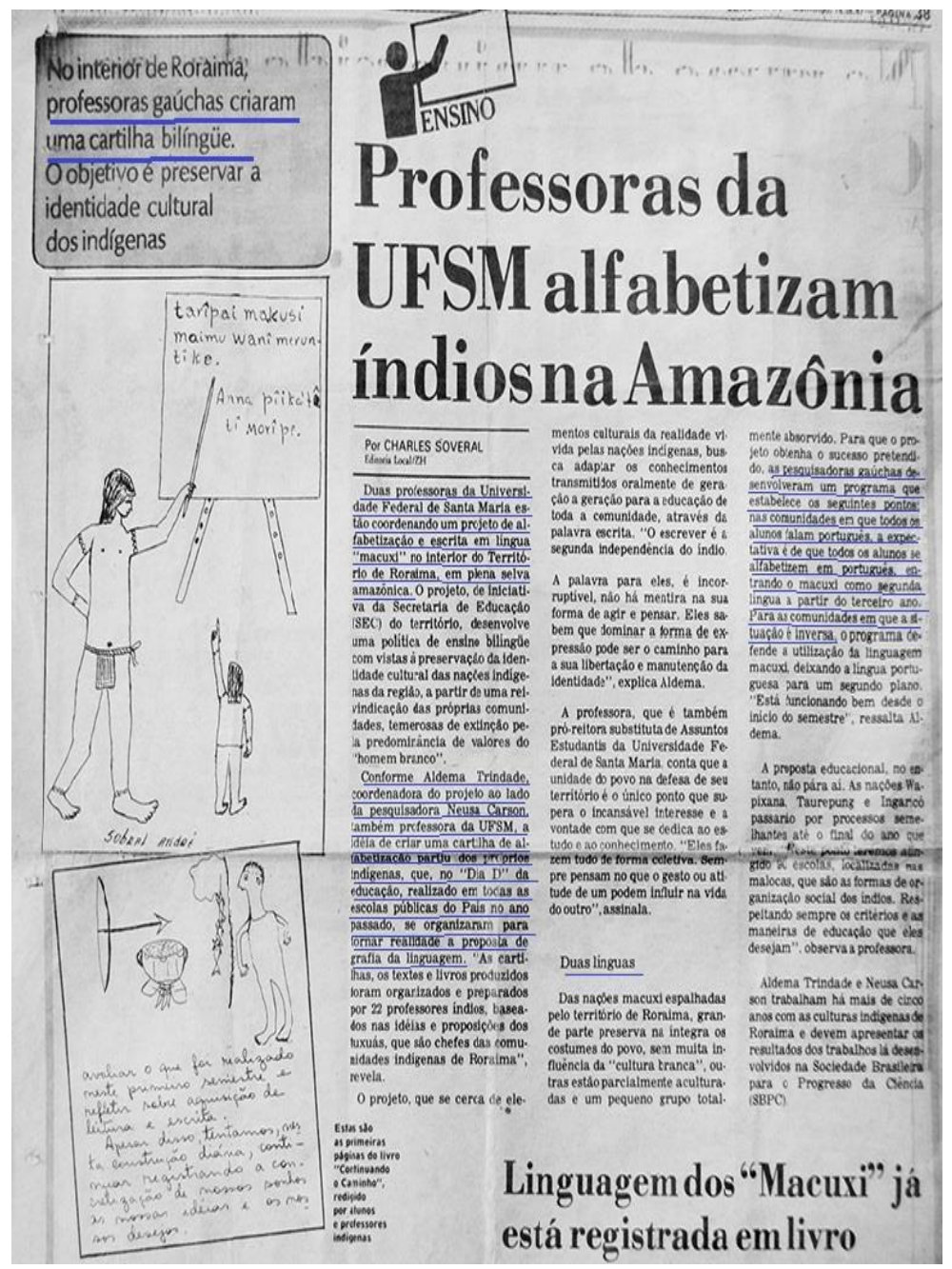

Figura 02 - Recorte do jornal Zero Hora, de 16 de agosto de 1987.

Como podemos observar nos trechos destacados nas Figuras 01 e 02, o texto jornalístico ressalta, principalmente, o papel das duas professoraspesquisadoras na elaboração das cartilhas. Conforme grifamos na figura 01, embora o texto mencione que o projeto é uma iniciativa da Secretaria da Educação, a presença da professora Aldema é enfatizada por meio da seguinte 
proposição: "criação e ajustamento de materiais de alfabetização para regiões indígenas". O texto também sublinha o fato de que esse trabalho havia sido iniciado pela professora Neusa Carson que, "há vários anos", pesquisa sobre a língua Macuxi.

Outro fato que nos chamou a atenção é que ambos os textos relatam a criação de uma cartilha bilíngue (chamada em destaque na figura 02, por exemplo), sendo que, na verdade, tínhamos uma cartilha Macuxi e uma cartilha em Português adaptada à realidade indígena. A proposta de alfabetização era bilíngue, e não o material didático, muito embora nos Cursos ministrados pela professora Aldema fossem elaborados textos coletivos em duas línguas ${ }^{11}$ (questão que abordaremos em outro texto).

Nas figuras a seguir, apresentamos imagens da configuração inicial desses dois materiais distintos: a cartilha para a alfabetização em Macuxi (Figuras 03 e 04) e a cartilha para a alfabetização em Língua Portuguesa (Figuras 05 e 06):
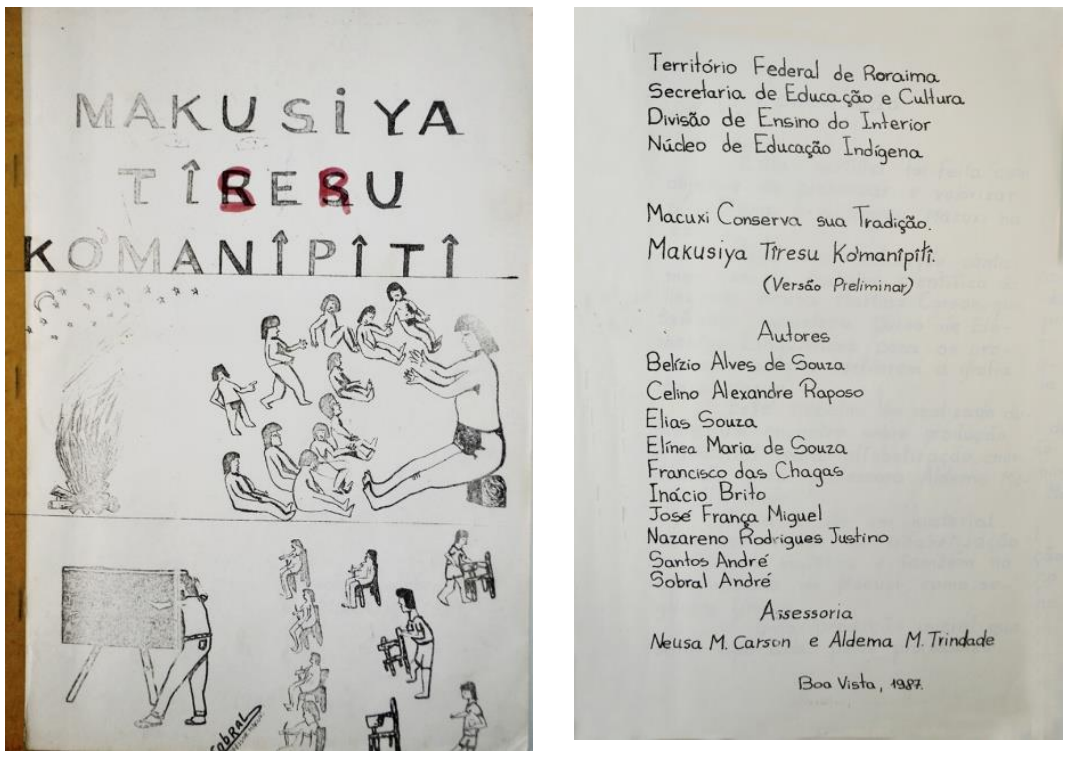

${ }_{11}$ Durante os encontros e cursos ministrados pela professora Aldema, os professores indígenas redigiam textos coletivos, os quais foram compilados na forma de um livro (manuscrito) intitulado, em Macuxi, Witin Komanípi Ematawirir, e, em português, Continuando o Caminho. Em alguns desses textos podemos encontrar relatos de experiências vivenciadas por eles no desenvolvimento das atividades pedagógicas realizadas a partir do uso desses materiais didáticos, bem como relatos sobre as atividades do grupo na produção desse material. 


\section{Apresentação}

Esta cartilha foi feita com objetivo de preservar e valorizar a cultura e a lingue Macuxi na. escola

Para sua realização conta. mos com o trabalho cientifico da linguista Neusa Martins Carson, que também ministrou Curso de Elémentos Linguísticos para os professores-autores definirem a grafia dessa lingua.

Este trabalho foi realizado durante um encontro sobre produçáo de material para alfabetizaçäo, coordenado pela professora Aldema Me. nine Trinolade.

$$
\text { Trata-se de um material }
$$
para ser usado na alfabetizaçäo na língua materna e também no aprendizado do Macuxi, como segunda lingua

será aplicada produç io inicial que indios, para ser avaliada, ampliada e aperfeiçoada. nhada E começo de uma camisonho. nhada a concretizaçáo de um

Figura 03 - Versão Manuscrita - Cartilha Macuxi, produzida no ano de 1987.

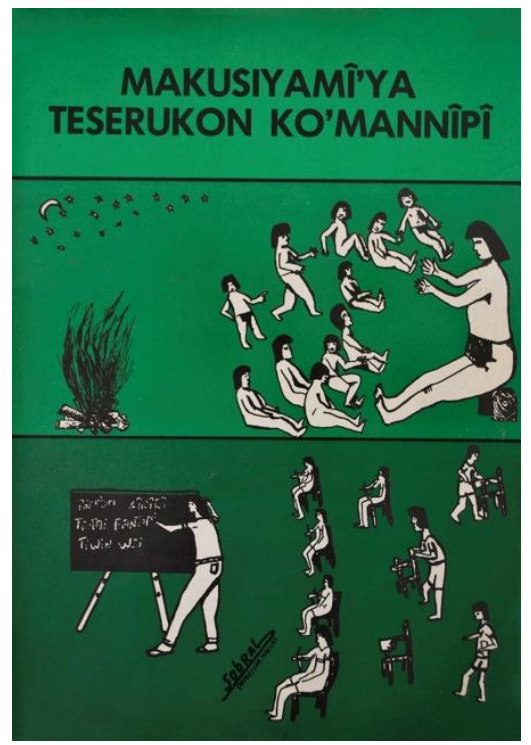




\section{Apresentação}

No momento em que a temática indigena vem ocupando, cada vez mais, espaço nas discussóes nacionais, surge esta 'Cartithe grupo que, aos poucos, vem desaparecendo, principo a cultura desse giöes de lavrado, onde o contoto com os brancos é mois acentuado.

O grupo macuxi é composto de aproximadamente $18 \mathrm{mi}$ indios, representando a maior população indigena de Roraima e ocupam a área NNE (Norte-Nordeste) do Território.

- Com a Cartiha Macuxi os professores indios terão um material didático mais eficiente para alfabetizar as crianças na sua lin-

A proposta de elaboraçāo de uma cartilha em Macuxi partiu de reivindicaçoes de lideranças e de educadores indigenas que a escola se tornasse verdadeiro espaço de preservacãonça de que de a criança india reafirmasse e volorizosse sua identidade, como participante e autora de sua própria história.

Esperamos que este trabalho sejo apenas o inicio de um

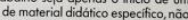
só do grupo macuxi, mas de outros grupos que vivem em Roraima. CILENE LAGO SALOMÃO
Secretária de Educoça e Culuro

\section{Ao Professor}

Com a implementação do projeto (Aprendendo com a Naureza), surgiv a necessidade de elaborar cartilhas que atendessem aos interesses das comunidades indigenas e fossem agradáveis e Essos crianças.

Essas cartilhas em Macuxi, Wapixana e Português apresentam características comuns e próprias, resultado da reflexão, da disAs palarras geradoras foram escolhidas pela carga signifiAs palavras geradoras foram escolhidas pela carga signifi-
cativa, oriundas de sua relevância sócio-cultural. Como essas pala-
vros nomeam referentes do cotidiono da criog vras nomeiam referentes do cotidiano da criança, não se faz necessário repeti-las pelo desenho impresso; a criança mesmo poderá representa-las. Procedendo, assim, ela irá ativar e exercitar sua criatividade, sua coordenação motora, sua conceptualização do objeto. Cada um, ilustrando sua cartilha, estará também personalizando-a, tornando-a mais sua.

Quanto à escrita, optou-se pelo sistema script por ser, do ponto de vista motor, mais fácil para o aluno; do ponto de vista construtivo da lingua escrita, por favorecer a percepção entre recorte so-

A cartilha é um dos materiais instrucionais de alfabetização usados em classe. A produtividade desse material, entretanto, depende muito da compreensão que o professor tem do processo de aquisição da leitura e da escrita e da efetiva motivação do alfabetizando para adquirir e desenvolver as quatro habilidades básicas da linguagem: ler e escrever, falar e ouvir.

Trata-se de um material para ser usado na alfabetização na lingua materna e também no aprendizado do Macuxi, como se-
gunda lingua.

Figura 04 - Versão Impressa - Cartilha Macuxi, impressa no ano de 1989.

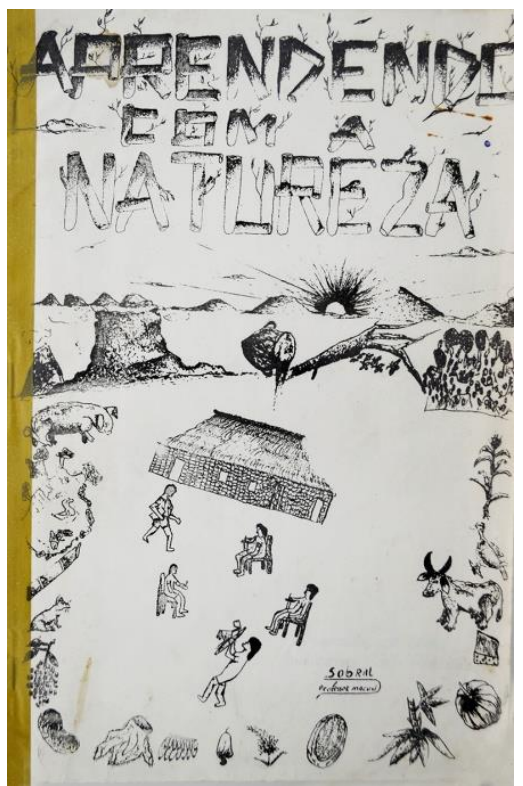

\section{Autores:}

Aldemir Jacinto Pimentel

Antônia da Conceição Pereira da Silva

Antônio Nogueira Batista

Belízio Alves de Souza

Celino Raposo

Elcimar Màduro Girão

Elínea Maria de Souza

Francisco da Chagas

Genival Thomé Macuxi

Helena Fidelis Raposo

Idelvânia Rodrigues Oliveira

Inácio Brito

José França Miguel

Justina da Costa Damascen

Maridete da Silva Benício

Marly de Souza

Nazinha Melquior de Lima

Raimunda Miguel

Úrsula Loiola Contreira

Sobral André

Assessoria:

Aldema Menine Trindade 


\section{Apresentação:}

Aproximar a Cartilha da realidade das Escolas e da Regiao, tornando sua linguagem mais acessivel e significativa para as crianças, foi o objetivo e "ânsia" de um grupo de profes sores que, de 16 a 20 de março e de 25 a 30 de junho de 1987, trabalhou intensamente,com carinho e dedicação, em encontros promovidos pelo Núcleo de Educação Indígena e coor. denado pela Professora Aldema Menine Trin dade.

Como este foi um entre outros tra balhos realizados em 80 horas, duas etapas, - tempo foi insuficiente para revisá-lo e completá lo. $\epsilon$, pois, o início de um trabalho que será retomado, discutido, ampliado e aper. feiçoado com todos aqueles que já o te rão testado com as crianças e que, com certeza, muito terão a contribuir.

E' também o início de um sonho que se concretiza.

Figura 05 - Versão Manuscrita - Cartilha Aprendendo com a Natureza, 1987.
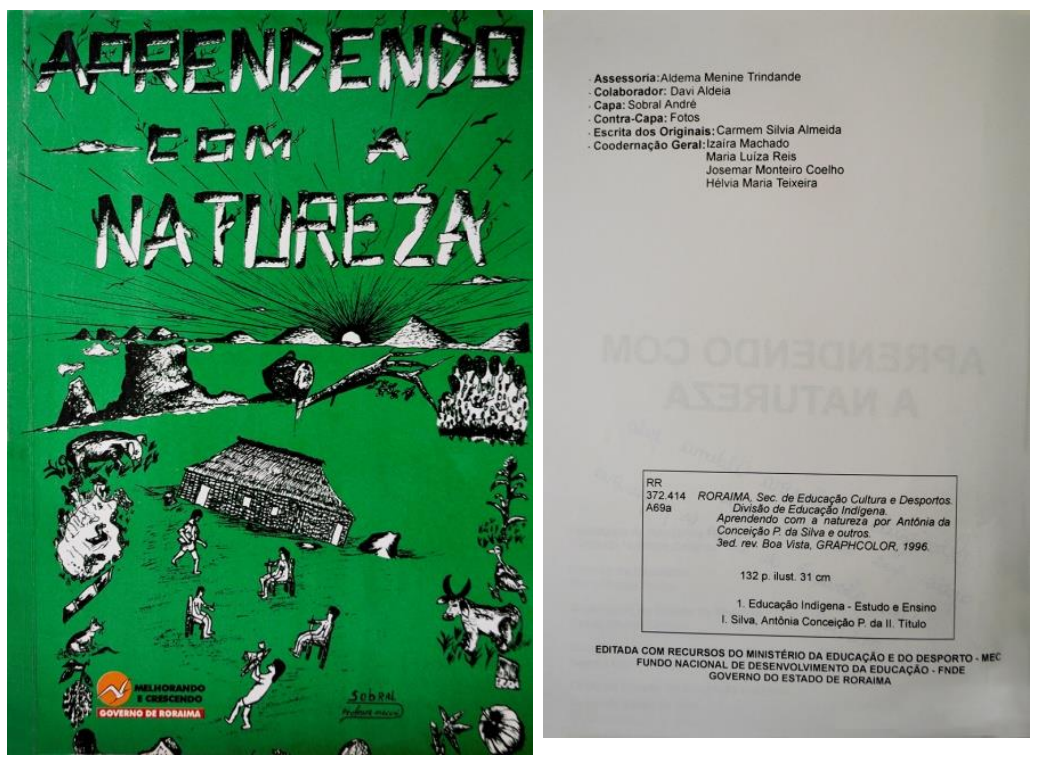
GOVERNO DO ESTADO DE RORAIM

作

DIVISÃO DE EDUCAÇÃO INDIGENA

\section{APRENDENDO COM A NATUREZA}

Autores:

-Antonia da Conceiçáo $\mathrm{P}$. da Silva - Celino Alexandre Raposo - Elcimar Maduro - Helena Fidelis Raposo - Inacio Brito - Jose França Migue - Jose Aldomar Borburema da Siva - Lindalva Nascimento Peicoto Maria Celene Gomes -Nazareno Rodngues Jusing - Odinetia Joato da Siva -Sobral Andro - Ursula Loyo -Umbeilina Veriat BOA VISTA
APRESENTAÇĀO

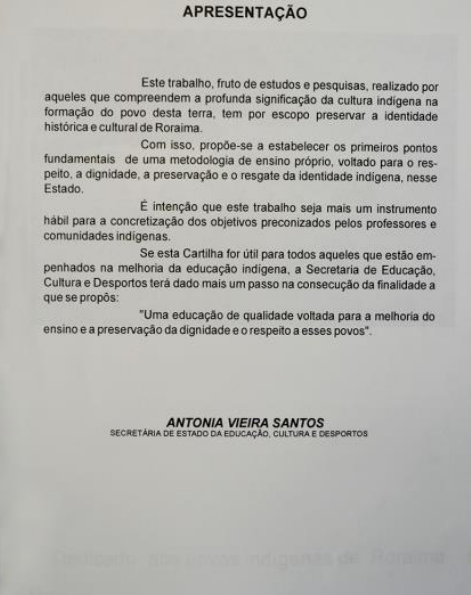

Figura 06 - Versão Impressa - Cartilha Aprendendo com a Naturez̨a, 1996.

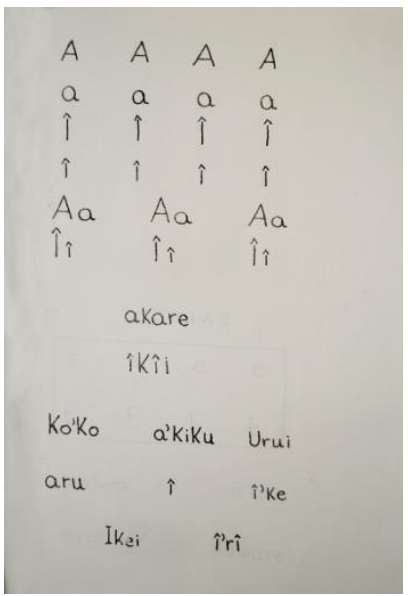

Versão Manuscrita

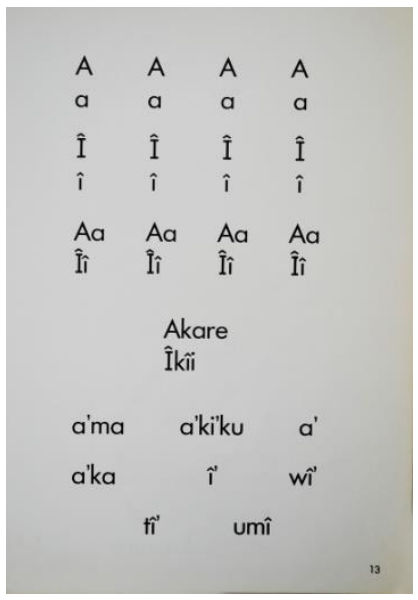

Versão Impressa

Figura 07 - Cartilha Macuxi - quadro comparativo. 

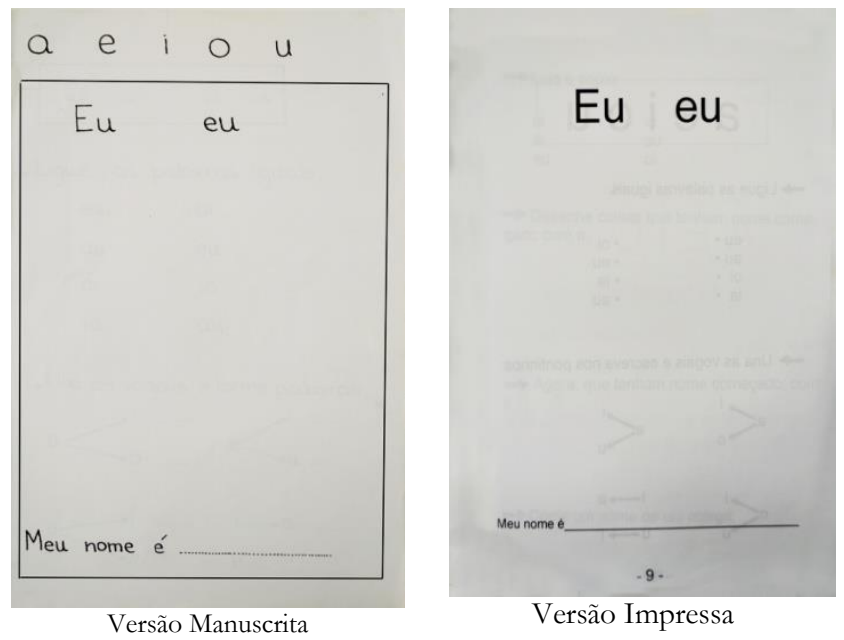

Figura 08 - Cartilha Aprendendo Com a Natureza - quadro comparativo.

O que tem permeado nossas reflexões, pautando nossas leituras e encaminhado nossas investigações é, de fato, o entendimento de algumas questões sobre a constituição/construção desses materiais didáticos, como por exemplo, o papel de cada uma das "assessoras", assim como eram nomeadas Neusa Carson e Aldema Menine Mckinney nas cartilhas, pela mídia, ou ainda, a compreensão das designações presentes no histórico do NEI, quais sejam, pesquisadora-linguista e educadora-linguista, respectivamente, em conjunto com a questão da autoria desses materiais.

A questão da autoria tem nos chamado a atenção, porque nos parece, pelas leituras feitas no arquivo até o momento, que há um apagamento do nome das assessoras na impressão das cartilhas em Macuxi, fato que não ocorre na impressão da cartilha em Língua Portuguesa.

$\mathrm{Na}$ Figura 03, que apresenta a cartilha Macuxi em sua versão manuscrita, temos a lista de autores, a nomeação das assessoras e uma apresentação da cartilha, criada por meio de um texto coletivo, discutido e elaborado pelos professores indígenas. Por se tratar de um texto coletivo, assim como toda a produção desse material, a apresentação dessa versão da cartilha não é assinada. Já na Figura 04, que traz a primeira versão impressa da cartilha ${ }^{12}$, na qual temos uma apresentação oficial realizada por um porta-voz

${ }^{12}$ Cabe destacar que essa primeira versão impressa é posterior à promulgação da Constituição da República Federativa do Brasil, de 05 de outubro de 1988, na qual consta, no parágrafo $2^{\circ}$, do $\underline{\text { artigo 210, que "O ensino fundamental regular será ministrado em língua portuguesa, assegurada }}$ 
do Estado, não encontramos nomeação de autoria para a cartilha; apenas em seção intitulada Ao professor temos referência à participação de professores no momento em se aborda o fato de que as cartilhas voltadas ao interesse indígena apresentam "características comuns e próprias" e que isso seria resultado da reflexão, da discussão e da experiência de todos os professores que as construíram (não há referência de que esses sejam os professores indígenas).

Outra versão impressa à qual tivemos acesso, datada de 1997, possui a mesma capa da edição anterior e apresentação também realizada por um representante institucional; porém, apresenta uma ficha catalográfica e nomeia 08 autores, entre os quais 06 figuravam entre os participantes da primeira versão apresentada na figura 03 , o que demonstra uma mudança de postura frente à questão da autoria.

Diferentemente do ocorrido com a cartilha Macuxi, na versão em Língua Portuguesa, o apagamento na nomeação dos autores e assessores parece-nos que não ocorreu, conforme podemos observar nos documentos a que tivemos acesso (ver Figuras 05 e 06). Na apresentação, feita por um representante do Estado, foi dado destaque para o fato de que "este trabalho foi fruto de estudos e pesquisa realizado por aqueles que compreendem a profunda significação da cultura indígena...".

Após uma primeira leitura nas versões manuscritas e nas versões impressas de ambas as cartilhas, observamos que poucas são as modificações na estrutura geral, tanto no que diz respeito às escolhas lexicais quanto nas formulações de enunciados de atividades. As modificações, alterações, são tangenciadas por questões políticas (política de Estado/política de línguas) tanto no tocante à questão da autoria quanto no tocante à questão da assessoria. Apagamentos, silenciamentos, deslocamentos de nomes, de lugares, de sentidos, perpassam a passagem da versão manuscrita (versão autorizada pelos sujeitos partícipes do processo de ensino-aprendizagem) para a versão impressa (versão autorizada pelo Estado).

\section{Considerações finais}

O olhar que temos lançado sobre os arquivos do FDAMM e do FDNC tem pautado, neste momento, nossas reflexões acerca do fazer científico da Linguística de campo (a formação do linguista ${ }^{13}$ ), das implicações

às comunidades indígenas também a utilização de suas línguas maternas e processos próprios de aprendizagem".

${ }^{13}$ Uma discussão relevante que contribui para essa questão no âmbito das ideias linguísticas, a meu ver, está apresentada no texto de Yonne Leite e Bruna Franchetto, intitulado $A$ concepção dos Linguistas, de 1983, publicado nos Cadernos de Estudos Linguísticos, n. 4, da Unicamp. 
teórico-metodológicas do saber do linguista e da elaboração de uma política de línguas.

Entendemos também que, ao produzirem as cartilhas, ao realizarem as escolhas dos termos que nelas constariam, ao decidirem quais textos seriam publicados nos livros bilíngues, quais histórias poderiam ser contadas, os professores indígenas já estavam, de alguma forma, imbricados em uma política linguística. Com isso, em nosso trabalho, não podemos deixar de considerar, que "no Brasil, a pluralidade linguística e cultural é uma marca de nascença, politicamente significada" (ORLANDI, 2009, p. 157). É importante colocar que estamos entendendo aqui política linguística como uma política sobre a língua e sobre a produção do conhecimento das línguas (cf. ORLANDI, 1998). A respeito do sentido mais importante de política linguística, Orlandi afirma: "podemos praticá-la não como vontade exclusiva do poder, mas como um trabalho que coloca em relação o político, o sujeito, a língua, as línguas e o saber sobre as línguas" (1998, p. 14).

Estamos buscando ainda compreender, com nossa pesquisa, o saber/ fazer sobre a língua que é produzido no âmbito das políticas públicas de expansão universitária e, principalmente, no âmbito da pesquisa linguística de campo. Para tanto, consoante Scherer (2009), afirmamos que toda a história do conhecimento é limitada por uma fronteira, seja ela espacial, histórica ou temporal.

Em relação a essas fronteiras, algo que nos intriga e nos impulsiona a essa investigação é o fato de que elas estão instaurando o contraditório, pois ora delimitam, ora aproximam, ora separam e ora unem o trabalho dessas duas professoras-pesquisadoras que se deslocam mais de 6.000 mil quilômetros para conhecerem a língua do outro e, indubitavelmente, ocuparem um lugar de autoridade sobre essa língua, sendo autorizadas tanto para ensiná-la como para descrevê-la. Nesse sentido, também nos questionamos: quais são as políticas linguísticas que aí estão postas em funcionamento? Conforme Orlandi (2009, p. 113), "uma das maneiras de se compreender o funcionamento do discurso sobre a língua é refletir sobre a política linguística".

\section{REFERÊNCIAS}

LEITE, Yonne; Franchetto, Bruna. A concepção dos Linguistas. Caderno de estudos linguísticos. Linguística Indígena e Responsabilidade Social, n. 4, 1983. Campinas, SP: UNICAMP/IEL/Departamento de Linguística, jun. 1983.

ORLANDI, E.P. Língua Brasileira e outras historias - Discurso sobre a língua e ensino no Brasil. Campinas, SP: RG, 2009. . Ética e Política Linguística. Línguas e Instrumentos Linguísticos, v. 1. Campinas: Pontes, 1998. 
SCHERER, A.E.; PETRI, V. et al. Arquivo, memória e acontecimento em uma política de Fundos Documentais. Gragoatá, Publicação dos Programas de Pós-Graduação do Instituto de Letras da Universidade Federal Fluminense, n. 34, 2013. Niterói: EdUFF, 2013 (no prelo). 